\title{
ADVANCED PROCEDURES FOR VOLCANIC AND SEISMIC MONITORING
}

\author{
ALESSIO DI IORIO ${ }^{1}$, SALVATORE STRAMONDO ${ }^{2}$, CHRISTIAN BIGNAMI ${ }^{2}$, \\ STEFANO CORRADINI ${ }^{2} \&$ LUCA MERUCCI $^{2}$ \\ ${ }^{1}$ Alma Sistemi sas (ALMA). \\ ${ }^{2}$ Istituto Nazionale di Geofisica e Vulcanologia (INGV).
}

\begin{abstract}
European Union FP7 APhoRISM project proposes the development and testing of two new methods to combine Earth Observation satellite data from different sensors and ground data. The aim is to demonstrate that this two types of data, appropriately managed and integrated, can provide new improved Copernicus Emergency products useful for seismic and volcanic crisis management. The first method, APE - A Priori information for Earthquake damage mapping, concerns the generation of maps to address the detection and estimate of damage caused by a seismic event. The novelty of APE relies on the exploitation of a priori information derived by InSAR time series to measure surface movements, shake maps obtained from seismological data, and buildings vulnerability information. The second method, MACE - Multi-platform volcanic Ash Cloud Estimation, concerns the exploitation of GEO sensor platform, LEO satellite sensors and ground measures to improve the ash detection and retrieval, and to characterize the volcanic ash clouds. INGV covers the role of project coordinator and ALMA Sistemi is participating in the exploitation and dissemination of the project results.

Keywords: ash concentration, damage mapping, data integration, emergency, satellite data.
\end{abstract}

\section{PROJECT OVERVIEW}

Satellite remote sensing has demonstrated to have unique capabilities in terms of spatial coverage, spatial density of measurements and synoptic view of the investigated area. At the same time ground-based techniques are better suited for point measurements with high accuracy, and generally better time repetition, but generally ensure scarce density and limited coverage. Although the scientific and technical background are different, the scientists dealing with the use of satellite and ground data more and more agree that these two sources of data have to be used together. APhoRISM is a project addressing the development of innovative products based on space and ground sensors and ground data to support the management and mitigation of the seismic and the volcanic risk. The objective of the project is to demonstrate that satellite remote sensing data and ground data, appropriately managed by means of novel methods, can provide new and improved products able to be used by the stakeholders for managing seismic and volcanic crisis and, stemming from a wider exploitation of available instruments, to achieve new performances in terms of accuracy and quality of information. The two proposed methods are called APE (A Priori information for Earthquake damage mapping) and MACE (Multi-platform volcanic Ash Cloud Estimation). APE addresses the generation of earthquake damage maps, and MACE is dealing with products useful for the volcanic ash characterization. The APhoRISM project consortium is composed by seven partners from five European Countries: Istituto Nazionale di Geofisica e Vulcanologia, 
Project Leader, Italy; Centre Tecnològic de Telecomunicacions de Catalunya, Spain; Bureau de Recherches Géologiques et Minières, France; Sapienza University of Rome, Italy; Gamma Remote Sensing Research and Consulting AG, Switzerland; University of Oxford, United Kingdom and ALMA Sistemi sas, Italy.

APhoRISM is funded under the 7th Frame Programme of European Commission, Grant Agreement n. 606738.

\section{THE APE METHOD}

The use of satellite data to investigate earthquake damages is not an innovative issue. Indeed, a wide literature and projects have addressed and focused such issue, but usually the proposed approaches are only based on change detection techniques and/or classifications algorithms. The novelty of APE (A Priori information for Earthquake damage mapping) consists on the exploitation of a priori information derived by using additional data coming from a) InSAR time series to measure surface movements and geological data, b) shakemaps obtained from seismological data, and c) vulnerability information.

The idea relies on the fact that this a priori information can be integrated with change detection maps (CDM), to improve their accuracy and to limit false alarms. The CDM are obtained from earth observation satellite sensors. Both Optical and/or Synthetic Aperture Radar (SAR) sensor are used for the change detection calculation. The logical scheme of APE is shown in Fig. 1 below.

The proposed approach can be divided into two phases: a preparedness phase and a crises phase. The preparedness phase concerns the generation of part of the a priori information dataset. This is based on the derivation of surface velocity maps by means of multi temporal InSAR technique [1], which is the integrated and jointly analyzed with geological information to obtain the an Seismic Instability factor. This latter is then merged with the building vulnerably to obtain the so called vulnerability scenario. When a seismic event occurs, the seismological data can provide the shakemap of the affected area. At this step the shakemap

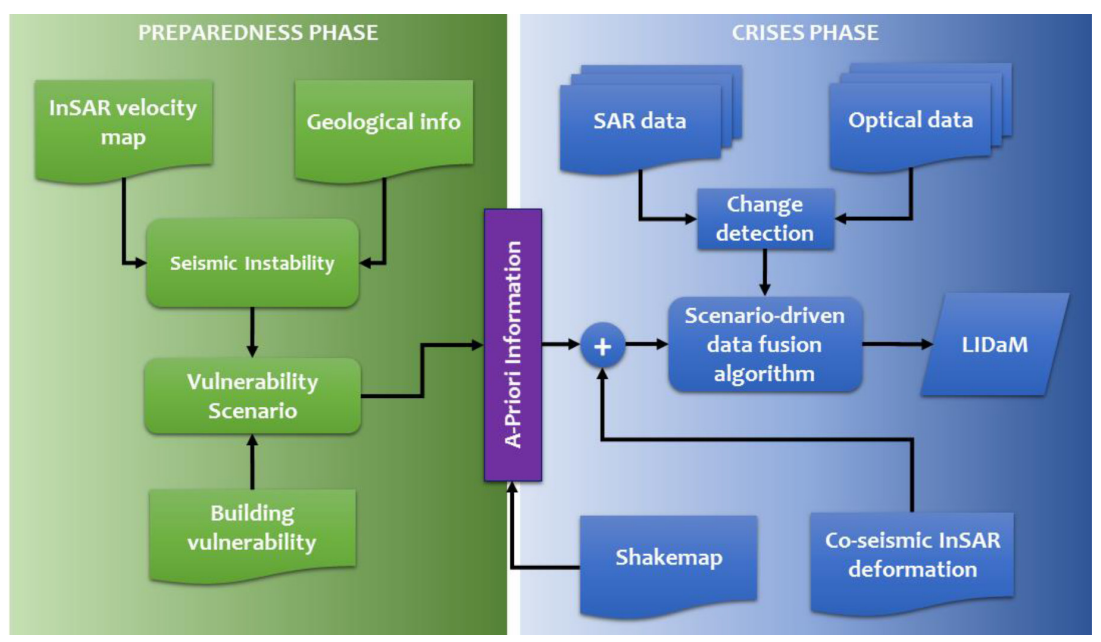

Figure 1: The logical scheme of the APE method. Green side (left) represents the preparedness phase, and the blue side (right) refers to crises phase. 
and the vulnerability scenario are integrated to derive the complete a priori information. This layer is then fused with the available CDMs, from optical and/or SAR images, and also surface deformation from Differential SAR interferometry [2]. Presently, two data fusion methods have been tested to merge change detection satellite features, vulnerability data and other non Earth Observation data. One method is based on a Naïve Bayesian Classification [3] approach, and the other exploits the Support Vector Machine [4] classification algorithm. The output is a Damage Map (see Fig. 2). This product will be derived at different scale depending on the satellite data resolutions. If very high resolution $(0.5-1.0 \mathrm{~m}$ per pixels) data are processed a single building scale map is calculated, where the damage level is expressed in terms of European Macroseismic Scale 98 [5]. If medium resolution (2.0-5.0 m per pixels)

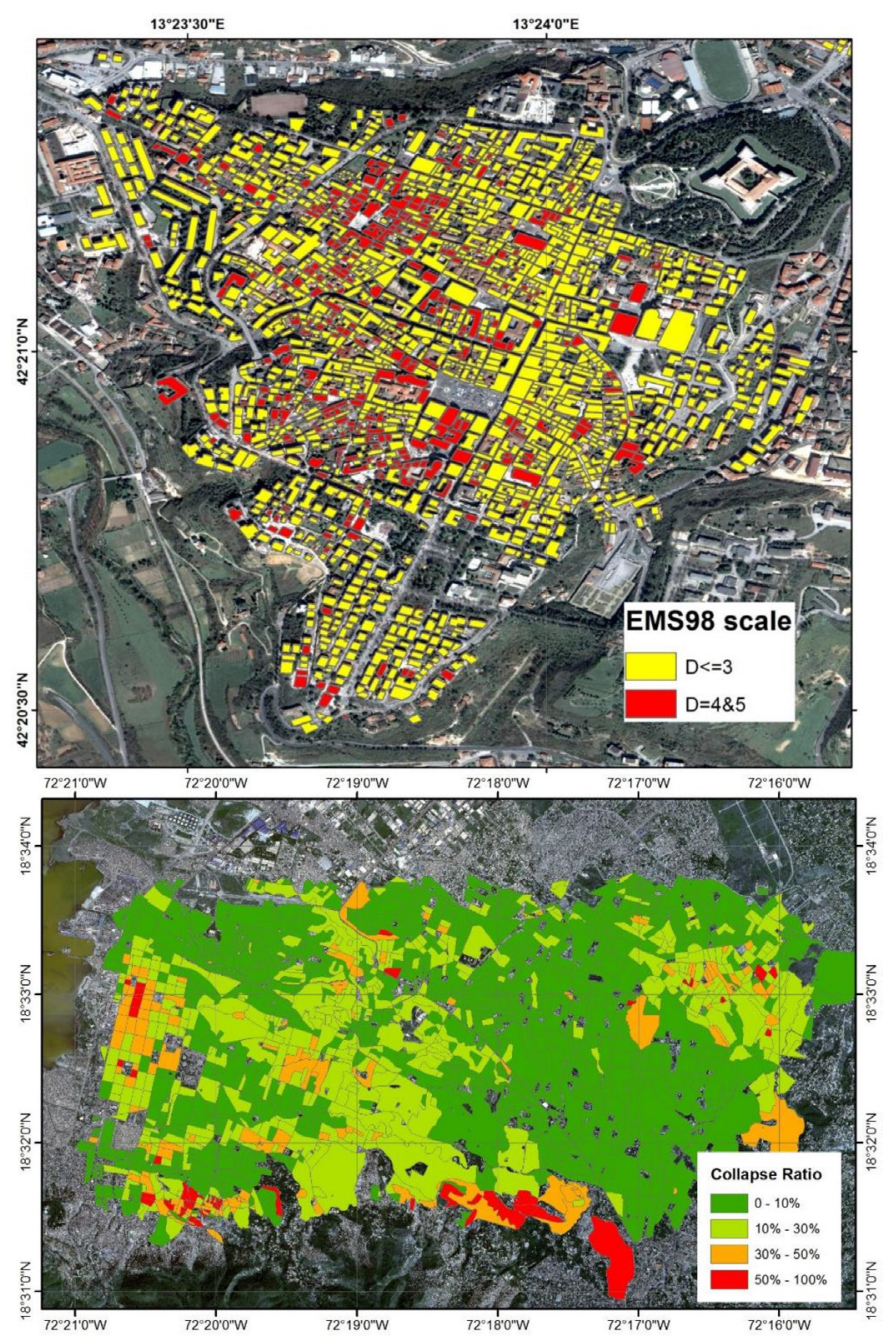

Figure 2: Examples of damage products: upper panel shows a damage map at single building scale (L'Aquila, Italy, April 6, 2009 earthquake), lower panel shows a city block damage map (Port-au-Prince, Haiti, January 12, 2010 earthquake). 
images are used the damage map is extracted at city block scale, and the damage level is expressed in terms of Collapse Ratio, i.e. the number of collapsed building divided by the total number of the buildings within the city block.

Some details about products generation can be found in Anniballe et al. [6], and Romaniello et al. [7], in preparation.

\section{THE MACE METHOD}

The volcanic eruptions represent one of the most important sources of natural pollution. Among gases, volcanoes emit particles of different sizes. The term 'volcanic ash' refers to coarse particles (i.e. up to $0.5 \mathrm{~mm}$ ). It is important because its effects on environment, climate and public health and because can be extremely dangerous to aircrafts. The volcanic ash particles could stall engines, abrade windscreens and damage sensitive avionics equipment. This is the reason why many flights were cancelled during the 2010 Eyjafjallajökull (Iceland) eruption causing major disruption to all of Europe. During such an eruption there was also the changing from the zero tolerance approach (flights are not permitted when volcanic ash is present in the atmosphere) to the definition of contamination areas based on ash concentration values by the European Aviation Safety Agency [8]. The introduction of such an ash concentration thresholds requires improvement on ash quantitative retrievals.

Worldwide volcanic activity is presently observed with an increasing variety of groundand space-based instruments to study its influence on the Earth system either at regional and global scales. Both satellite- and ground-based methodologies have advantages and drawbacks. The Multi-platform volcanic Ash Cloud Estimation (MACE) procedure will exploit the complementarity between geostationary (GEO) and polar (LEO) satellite sensors and ground measurements to improve the ash detection and retrieval and to entirely characterize the volcanic ash clouds from source to the atmosphere. The basic idea behind MACE consists to improve the volcanic ash retrievals at the space time scale of typical geostationary observations using both the LEO satellite estimations and in situ data. The typical ash retrieval in the thermal infrared (TIR) spectral range will be integrated by using visible (VIS) and microwave (MW) measurements. The ash detection will be extended also in case of cloudy atmosphere. The MACE integration techniques will run continuously on global scale.

MACE is based on two main steps: a background and a foreground process (see Fig. 3). The background process consists of estimating the volcanic ash from available GEO measurements (inversion step) and to collocate the LEO and ground sensor ash retrievals (collocation step, COL). The result of this step is to obtain a data set containing the co-located per-pixel ash retrievals derived from LEO, GEO and ground data. This process will be continuously ongoing, since new LEO, GEO and ground data are continuously ingested on a global scale. A pre-processing (PRE) stage is accomplished after each background process. A foreground process is based on the computation of the integrated ash-observable (ash mass, effective radius, AOD, height and thickness of the ash cloud) (integration step, INT). The GEO-based retrieval relationships are updated every time a new set of combined LEO-based and ground-based data have been added to the data set. To assure that only the most recent ash history is captured and to guarantee a statistical significance of the training set, the ash-observable inverse relationship for a given sub-region is derived using only the most recent combined data. The last step is represented by the prediction of the ash from GEO-IR measurements in a given sub-region by applying the derived ash retrieval algorithm (retrieval step, RET). 


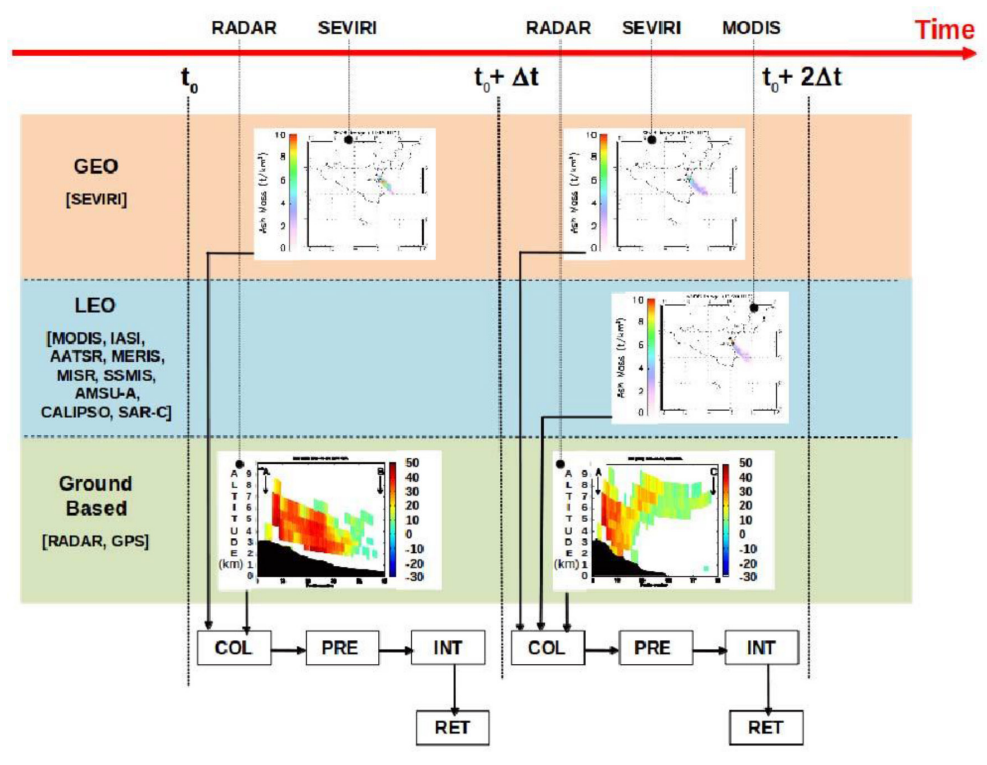

Figure 3: MACE temporal flow diagram. For each time interval, the available satellite and ground measurements are spatially collocated (COL), pre-processed (PRE), integrated (INT) and finally the new retrieval product released (RET).

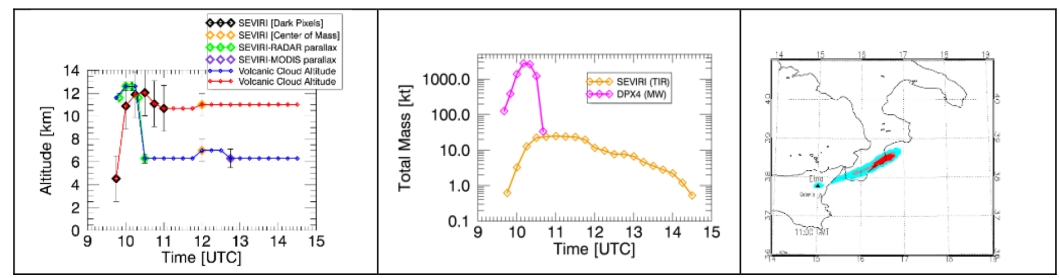

Figure 4: Left panel: volcanic cloud layers. Middle panel: ash mass. Right panel: ash concentration (Low contamination area (cyan); medium contamination area (grey); high contamination area (red)). From Corradini et al. 2016.

As GEO data the MSG-SEVIRI measurements will be considered. The LEO systems used for the ash products integration are MODIS, MERIS, IASI, AATSR, MISR, SSMIS, AMSU-A, CALIPSO and SAR-C, while on ground the GPS and MW radar systems will be taken into account. The MACE outputs (i.e. the integrated ash products) will be: ash detection, mass, effective radius, optical depth, concentration and volcanic cloud altitude. All the products will be delivered in clear sky condition, with the exception of the ash detection map that will be delivered also in cloudy sky conditions.

Figure 4 shows the results obtained from the integration between satellite- and groundbased systems applied to the Etna 23 November 2013 lava fountain $[9,10]$.

All the products have been validated by using ground-based cameras, HYSPLIT model and ground deposit. 


\section{IMPACT}

The 2010 volcanic eruption in Iceland closed European airports for six days. Over 107,000 flights had been cancelled all across Europe during the six-day travel ban accounting for $48 \%$ of total air traffic and roughly 10 million passengers were forced on ground. As a result a single event caused direct economic losses for about 1,400 $\mathrm{M} €$ and a non-negligible part of it was due to the flight bans that normally operate in a conservative way. The above figure are only the direct cost but this type of events does not affect air traffic only; they will cause losses on the travel industry with estimated losses of \$5-10 billion a week as well as to the stock prices of European airlines, as well as other travel-related industries including shippers such as FedEx and UPS.

Taking an estimated, average elapsed time of 30 years between two severe events, the direct impact on the European market is assessed in 46,7 M€/year of direct costs. In case we consider the indirect impact on the travel industry, this figure rise up to $300 \mathrm{M} €$ per year.

The APhoRISM proposed methodologies can provide much better and precise assessment for the sake of the decision maker with important consequences on the time duration and air space area subjected to the flight ban. In fact MACE is estimated to provide between $7 \%$ and $10 \%$ better performance with respect to the currently used methodologies with a potential, estimated impact of $30 \mathrm{M} € /$ year of cost saving on the European market. The actual figure of the improvement with regard the current used methodologies will be assessed during the project implementation.

For the damage assessment tool APE two areas of interest have been identified matching with the intermediate and final product of the methodology:

- Insurance market for householder is addressed by the intermediate product 'seismic instability and vulnerability maps'

- Emergency response mainly concerning Civil Protection operability is addressed by the final damage mapping products

The insurance market for householders is quite complex and has a number of specific laws and regulations different from country to country that strongly impact in the market assessment; nevertheless the economic importance is well recognized specifically in the developed countries. In the frame of APhoRISM project we will focus the market analysis of the APE method in Europe, Japan and US markets.

For the emergency response addressed by the damage mapping products the market analysis will focus on the improved operative responses of the Civil Protection to a seismic event. In this respect APE will provide the Civil Protection with an unprecedented tool to address the logistic of the intervention during the few ten hours after the recording of the seismic event.

In fact, during the recent earthquake in L'Aquila, Italy, with a total death toll of 308, the major intervention has been concentrated in the city of L'Aquila, while entire villages in the area were neglected for several hours because the information were not sufficient to define a reliable priority lists. At Onna, located few Km from L'Aquila and where the major death tool has been recorded, (200 causalities over 600 inhabitants) the first organized aid arrived after 7 hours from the seismic event and some remote fractions around the city were reached only after 24 hours.

The availability of the damage maps within few hours from the event would have driven the first aid where the major damage was assessed. There is no doubt that a prompt rescue 
intervention where it was mostly needed would have strongly reduced the death tool and injuries by a considerable fraction.

The exploitation task of the project APhoRISM will analyze this particular aspect trying to give realistic figures and performing simulations based on the L'Aquila earthquake scenario.

\section{CONCLUSION}

Innovative, affordable solutions like the proposed MACE method and the seismic damage assessment tool (APE) will provide novel 'tools' to improve the general safety of civil aviation transport and emergency management response to severe events.

The project will mainly focus on the technical aspects of the proposed innovative methodologies, but it will also take into account their impact in terms of cost savings, new products for the markets and improved response of the civil protections directly mapping on lifesaving statistics.

The project started in December 2013 and activities are currently on-going. Preliminary results will be presented in the oral presentation.

\section{ACKNOWLEDGEMENTS}

The present work has been funded by the EC-FP7 APhoRISM project (Research, Technological Development and Demonstration Activities, grant agreement n. 606738).

\section{REFERENCES}

[1] Werner, C., Wegmuller, U., Strozzi, T. \& Wiesmann, A., Interferometric point target analysis for deformation mapping. IEEE Proceeding Geoscience and Remote Sensing Symposium, 7, pp. 4362-4364, 2003, doi:10.1109/IGARSS.2003.1295516 http://dx.doi.org/10.1109/IGARSS.2003.1295516

[2] Massonnet, D. \& Feigl, K.L., Radar interferometry and its application to changes in the earth's surface. Reviews of Geophysics, 36(4), pp. 441-500, 1998. http://dx.doi.org/10.1029/97RG03139

[3] Cou'e, C., Fraichard, T., Bessi`ere, P. \& Mazer, E., Multi-sensor data fusion using Bayesian programming: an automotive application. In Proceedings of the IEEE/RSJ International Conference on Intelligent Robots and Systems, pp. 141-146, 2002.

[4] Cortes, C. \& Vapnik, V., Support-vector networks. Machine Learning, 20(3), pp. 273 297, 1995. http://dx.doi.org/10.1007/BF00994018

[5] Grünthal, G. (ed), European Macroseismic Scale 1998 (EMS-98). Cahiers du Centre Européen de Géodynamique et de Séismologie 15, Centre Européen de Géodynamique et de Séismologie. Luxembourg, p. 99, 1998.

[6] Anniballe, R., Chini, M., Pierdicca, N., Bignami, C., Stramondo, S., Noto, F., Scalia. T., Martinelli, A. \& Mannella, A., Detecting earthquake damage in urban area: application to Cosmo-SkyMed imagery of L'Aquila earthquake. Proceeding SPIE 9642, SAR Image Analysis, Modelling, and Techniques, 15 96420C, 2015. http://dx.doi.org/10.1117/12.2195723

[7] Romaniello, V., Piscini, A., Bignami, C. \& Stramondo, S., Earthquake damage assessment over Port-au-Prince (Haiti) by fusing optical and SAR satellite data. In preparation.

[8] European Aviation Safety Agency (EASA), Safety information bulletin No.: 201017R7, available at http://www.ad.easa.europa.eu/ad/2010-17R7 (accessed on 16 November 2015). 
[9] Merucci, L., Zakšek, L., Carboni, E. \& Corradini, S., Stereoscopic estimation of volcanic cloud-top height from two geostationary satellites. Remote Sensing, Special Issue on Volcano Remote Sensing, 8(3), p. 206, 2016.

http://dx.doi.org/10.3390/rs8030206

[10] Corradini, S., Montopoli, M., Guerrieri, L., Ricci, M., Scollo, S., Merucci, L., Marzano, F.S., Pugnaghi, S., Prestifilippo, M., Ventress, L., Grainger, R.G., Carboni, E., Vulpiani, G. \& Coltelli, M., A multi-sensor approach for the volcanic ash cloud retrievals and eruption characterization. Remote Sensing, Special Issue on Volcano Remote Sensing, 8(1), p. 58, 2016.

http://dx.doi.org/10.3390/rs8010058 